\title{
Baseline characteristics and risk factors for ulcer, amputation and severe neuropathy in diabetic foot at risk: the BRAZUPA study
}

Maria Candida R. Parisi ${ }^{1,10^{*}}$, Arnaldo Moura Neto', Fabio H. Menezes', Marilia Brito Gomes², Rodrigo Martins Teixeira², José Egídio Paulo de Oliveira ${ }^{3}$, Joana Rodrigues Dantas Pereira ${ }^{3}$, Reine Marie Chaves Fonseca ${ }^{4}$, Lorena Barreto Arruda Guedes ${ }^{4}$, Adriana Costa e Forti ${ }^{5}$, Ana Mayra Andrade de Oliveira ${ }^{6}$, Marta Barreto de Medeiros Nóbrega ${ }^{7}$, Víctor Nóbrega Quintas Colares ${ }^{7}$, Helena Schmid ${ }^{8,9}$, Otto Henrique Nienov ${ }^{8,9}$, Marcia Nery ${ }^{10}$, Túlio Diniz Fernandes ${ }^{10}$, Hermelinda C. Pedrosa ${ }^{11}$, Cristina da S. Schreiber de Oliveira ${ }^{12}$, Marcelo Ronsoni ${ }^{12}$, Karla Freire Rezende ${ }^{13}$, Maria Teresa Verrone Quilici ${ }^{14}$, Alexandre Eduardo Franzin Vieira ${ }^{14}$, Geisa Maria Campos de Macedo ${ }^{15}$, Eliana Gabas Stuchi-Perez ${ }^{16}$, Kandir Genésio Innocenti Dinhane ${ }^{17}$, Ana Emilia Pace ${ }^{18}$, Maria Cristina Foss de Freitas ${ }^{18}$, Maria Regina Calsolari ${ }^{19}$ and Mario José Abdalla Saad ${ }^{1}$

\begin{abstract}
Background: Studies on diabetic foot and its complications involving a significant and representative sample of patients in South American countries are scarce. The main objective of this study was to acquire clinical and epidemiological data on a large cohort of diabetic patients from 19 centers from Brazil and focus on factors that could be associated with the risk of ulcer and amputation.
\end{abstract}

Methods: This study presents cross sectional, baseline results of the BRAZUPA Study. A total of 1455 patients were included. Parameters recorded included age, gender, ethnicity, diabetes and comorbidity-related records, previous ulcer or amputation, clinical symptomatic score, foot classification and microvascular complications.

Results: Patients with ulcer had longer disease duration (17.2 \pm 9.9 vs. $13.2 \pm 9.4$ years; $p<0.001$ ), and poorer glycemic control (HbA1c $9.23 \pm 2.03$ vs. $8.35 \pm 1.99 ; p<0.001)$. Independent risk factors for ulcer were male gender (OR $1.71 ; 95 \%$ Cl 1.2-3.7), smoking (OR 1.78; $95 \%$ Cl 1.09-2.89), neuroischemic foot (OR 20.34; $95 \%$ Cl 9.31-44.38), region of origin (higher risk for those from developed regions, OR 2.39; $95 \% \mathrm{Cl}$ 1.47-3.87), presence of retinopathy (OR 1.68; $95 \% \mathrm{Cl} 1.08-2.62)$ and absence of vibratory sensation (OR 7.95; $95 \% \mathrm{Cl} 4.65-13.59)$. Risk factors for amputation were male gender (OR 2.12; 95 \% Cl 1.2-3.73), type 2 diabetes (OR 3.33; 95 \% Cl 1.01-11.1), foot at risk classification (higher risk for ischemic foot, OR 19.63; $95 \%$ Cl 3.43-112.5), hypertension (lower risk, OR 0.3; $95 \%$ Cl 0.14-0.63), region of origin (South/Southeast, OR 2.2; 95 \% Cl 1.1-4.42), previous history of ulcer (OR 9.66; $95 \%$ Cl 4.67-19.98) and altered vibratory sensation (OR 3.46; 95 \% Cl 1.64-7.33). There was no association between either outcome and ethnicity.

Conclusions: Ulcer and amputation rates were high. Age at presentation was low and patients with ulcer presented a higher prevalence of neuropathy compared to ischemic foot at risk. Ischemic disease was more associated with amputations. Ethnical differences were not of great importance in a miscegenated population.

Keywords: Diabetes, Risk factors for ulcer, Amputation, Severe neuropathy, Brazil

\footnotetext{
*Correspondence: emaildacandida@uol.com.br

${ }^{1}$ Faculty of Medical Sciences, State University of Campinas, Campinas,

SP 13083-887, Brazil

Full list of author information is available at the end of the article
} 


\section{Background}

The rising prevalence of diabetes around the world has dramatically increased the number of people bearing complications of this potentially incapacitating disease [1]. Peripheral neuropathy and diabetic foot are among the most feared. They frequently terminate in ulcer, infection and amputation, significantly reducing quality of life [2]. The life expectancy of a person with lower limb amputation is comparable to that of other serious diseases, such as aggressive types of cancer or advanced congestive heart failure $[3,4]$.

Additionally, it is estimated that one person undergoes amputation every $20 \mathrm{~s}$ around the globe as a complication of diabetes and that up to $85 \%$ of these procedures could be prevented with adequate screening [5].

The incidence of diabetes is rising more rapidly in developing regions such as Latin America and Southeast Asia than in Western Europe or North America [1, 6], putting a serious economic burden on the healthcare budgets of these nations. Given the disparities in health care access and the social, economic and ethnic differences between these regions, it is crucial to gain knowledge of the clinical characteristics and epidemiology of foot at risk in different areas of the world.

Additionally, several studies have highlighted the dissimilarities in diabetes incidence, management, prevalence and metabolic control, as well as risk and clinical evolution of foot complications [7, 8]. Studies on foot ulcers involving a significant and representative sample of patients such as the EURODIALE cohort [9] are scarce, especially in developing regions. In Brazil, in addition to the lack of descriptive data on foot at risk and ulcer prevalence, there are great dissimilarities between different regions regarding access to health care and socioeconomical structure that could lead to different presentations of foot at risk and diabetic foot complications.

Therefore, our aims were to acquire data on the clinical and epidemiological characteristics of a large cohort of patients from several centers in our country, all specializing in the evaluation and care of patients with diabetes and focus on factors that could be associated with the risk of ulcer and amputation.

\section{Methods}

This study presents cross sectional, baseline results of the Brazilian Cooperative Study on Ulcer, Severe Peripheral Neuropathy and Amputation (BRAZUPA), which is funded by the National Institute of Science and Technology-Obesity and Diabetes Division, in order to gather data on the current situation of foot at risk throughout the nation. One thousand fifty-five consecutive patients referred for evaluation of foot at risk to 19 different specialized diabetic centers in the country were included in the study. Among these, six included diabetic foot care units and the others started to structure theirs after the study beginning. Patients were referred from primary care facilities according to Brazilian National Health System (SUS) standard proceedings. All data were collected between June 2012 and July 2014 and each center submitted data collected during the first year after study entry. The four most populous of the country's five administrative regions were included, and the data can be considered representative for the whole country (around 200 million people at the time the study was initiated)-Fig. 1.

Trained personnel collected data during patients' routine evaluations and from the medical records of each institution. Data were collected on a standardized electronic sheet developed during a 6-month long pilot study involving 14 centers, simplified to allow input without compromising the routine care of patients. Dedicated personnel were trained in each center during the pilot study. The data collected was submitted to the coordinating center at the end of the first year (University of Campinas, Campinas, Sao Paulo, Brazil), where it was analyzed as a whole after all centers had submitted their information. Patient characteristics recorded included age, gender, ethnicity (white Latin, African descent, mixed ethnicity and Asian), diabetes and

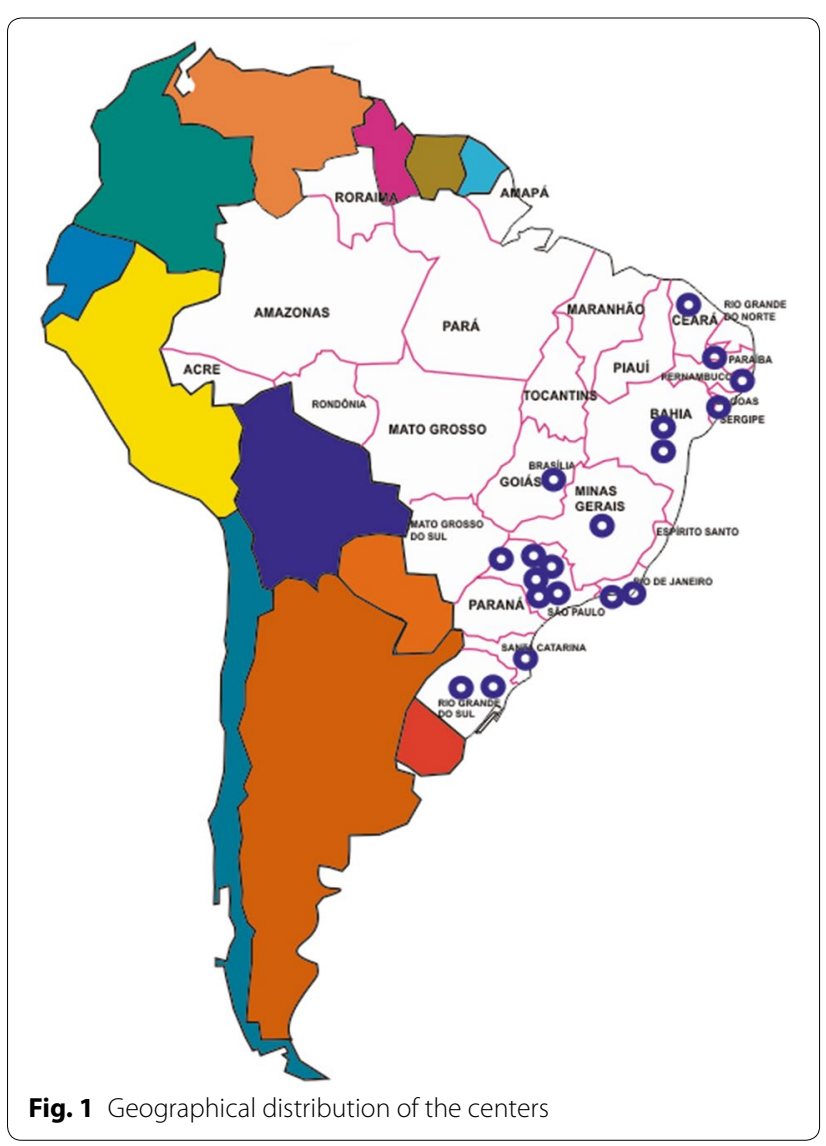


comorbidity related records, previous ulcer or amputation, symptom characteristics and clinical symptomatic score.

Foot at risk was classified as without risk, neuropathic, ischemic or neuroischemic. Neuropathy was defined as a positive result in clinical or symptomatic scores and/or an abnormal sensitivity test using a $10 \mathrm{~g}$ Semmes-Weinstein monofilament. Vibratory sensation was classified as present, diminished or absent according to the results of the $128 \mathrm{~Hz}$ tuning fork examination [5]. Ischemia was defined as diminished or absent pedal pulses or decreased ankle-brachial pressure index $(\mathrm{ABI}<0.9)[5$, 10]. Amputations were classified as minor (below the ankle) or major (ankle or higher). Ulcers were evaluated for their prevalence and etiological origin: ischemic, neuropathic or neuro-ischemic.

The presence of other microvascular complications was also evaluated. Retinopathy was assessed by standard fundoscopy by a trained ophthalmologist at each center and nephropathy by the presence of microalbuminuria and/or abnormal creatinine clearance (calculated using the Cockroft-Gault formula). Visual impairment was defined as abnormal Snellen chart test result despite the use of corrective lenses. Renal impairment was defined as creatinine clearance $<60 \mathrm{ml} / \mathrm{min} / 1.73 \mathrm{~m}^{2}$.

The study was approved by each institution's ethics in research committee as well as by the coordinating center's Ethics Committee.

\section{Statistical analysis}

Categorical data is shown as percentages; continuous variables as means (standard deviation-SD).

Comparison between groups of categorical data was made using the Chi Square test. Differences in continuous variables between two groups were evaluated by Student's t test.

Independent risk factors for ulcer and amputation were assessed by multiple logistic regression analysis. The model for ulcer included age, gender, type of diabetes, disease duration, ethnicity, BMI, smoking status, foot at risk classification (foot without risk as reference category), vibratory sensation, visual impairment, hypertension, renal impairment and macro region of origin. Adjustments were done by the forward conditional method. The model for amputation included all of the abovementioned variables with the addition of history of previous ulcer episode.

Statistical analysis was performed with SPSS version 20.0 (IBM Inc.). Significance was defined as a $\mathrm{p}$ value $<0.05$.

\section{Results and discussion}

\section{Patient characteristics}

Baseline patient characteristics are summarized in Table 1 . The mean age and disease duration of
Table 1 Clinical and epidemiological characteristics of study participants

\begin{tabular}{|c|c|}
\hline Variable & Mean (SD)/\% \\
\hline Age & $57.7(14.2)$ \\
\hline Sex (female/male) & $58.6 / 41.4$ \\
\hline $\mathrm{BMI}\left(\mathrm{kg} / \mathrm{m}^{2}\right)$ & $29.3(6.2)$ \\
\hline \multicolumn{2}{|l|}{ Ethnicity } \\
\hline White & 53.8 \\
\hline Black & 18.4 \\
\hline Mixed & 20.8 \\
\hline Asian & 7.0 \\
\hline Type of diabetes (1/2) & $9.3 / 90.7$ \\
\hline Diabetes duration (years) & $14.2(9.8)$ \\
\hline $\mathrm{HbA1c}(\%)$ & $8.56(2.03)$ \\
\hline Smoking & 24.2 \\
\hline Hypertension & 81.5 \\
\hline Cardiopathy & 28.5 \\
\hline Dyslipidemia & 72.9 \\
\hline \multicolumn{2}{|l|}{ Nephropathy } \\
\hline Stage 1 & 52.1 \\
\hline Stage 2 & 25.4 \\
\hline Stage 3 & 15.8 \\
\hline Stage 4 & 1.9 \\
\hline Stage 5 & 4 \\
\hline Retinopathy & 46.2 \\
\hline Visual impairment & 50.3 \\
\hline Previous ulcer & 25.3 \\
\hline Active ulcer & 18.6 \\
\hline Amputation & 13.7 \\
\hline Minor & 82.7 \\
\hline Major & 17.3 \\
\hline \multicolumn{2}{|l|}{ Foot at risk classification } \\
\hline Foot without risk & 37.8 \\
\hline Neuropathic & 33.7 \\
\hline Ischemic & 8.5 \\
\hline Neuroischemic & 20 \\
\hline \multicolumn{2}{|l|}{ Vibratory sensation } \\
\hline Normal & 55.7 \\
\hline Diminished & 29.9 \\
\hline Absent & 14.5 \\
\hline \multicolumn{2}{|l|}{ Score of symptoms } \\
\hline Normal & 20.4 \\
\hline Mild & 29.6 \\
\hline Moderate & 28.1 \\
\hline Severe & 22 \\
\hline Treatment of neuropathy (yes) & 14.1 \\
\hline \multicolumn{2}{|l|}{ Region } \\
\hline South & 18.9 \\
\hline Southeast & 38.9 \\
\hline Midwest & 3.4 \\
\hline Northeast & 38.8 \\
\hline
\end{tabular}


participants was 57.67 (14.23) years and 14.21 (9.77) years, respectively. The majority of patients were female (58.6\%), White (53.8 \%) and had type 2 diabetes (90.7\%). Nearly a quarter $(25.3 \%)$ of patients had a previous history of ulcer and $13.7 \%$ of amputation (17.3\% of these were major amputations). One in every twenty patients (5.3\%) had undergone more than one amputation procedure. One-third of patients had neuropathic foot (33.7 \%) and only $8.5 \%$ had ischemic disease alone. Nearly onefifth $(18.6 \%)$ of all evaluated patients presented a current, active foot ulcer at evaluation.

\section{Differences between patients with and without amputation, ulcer and mild versus moderate/ severe neuropathy \\ Ulcer}

We observed a significantly larger proportion of men with a previous history of ulcer (35.7 vs. $18 \%$; $\mathrm{p}<0.001)$. These patients also had longer disease duration $(17.2 \pm 9.9$ vs. $13.2 \pm 9.4$ years; $\mathrm{p}<0.001)$, and poorer glycemic control (HbA1c $9.23 \pm 2.03$ vs. $8.35 \pm 1.99$; $\mathrm{p}<0.001)$. Those of White or Mixed ethnicities had a higher proportion of ulcer than Black and Asian ethnicities (29 and 24.6 vs. 19.7 and $16.5 \%$, respectively; $\mathrm{p}=0.008$ ). There was a higher prevalence of previous ulcer in those with retinopathy (38.3 vs. $14.1 \%$; $\mathrm{p}<0.001)$, visual (30.8 vs. $18 \%$; p < 0.001) and renal impairment (34.8 vs. $22.7 \%$; $<0.001$ ). Ulcer was less common in patients with ischemic foot than neuropathic or neuro-ischemic classifications (14.2 vs. 39.3 and $45.1 \%$, respectively; $\mathrm{p}<0.001$ ). Individuals from the economically developed regions (South/Southeast) had a higher prevalence of previous ulcer episode than those coming from economically emerging ones (Midwest/ Northeast) (28.8 vs. $20.7 \%$, respectively; $\mathrm{p}=0.001$ ).

Table 2 shows the prevalence of different clinical characteristics in patients with and without ulcers.

\section{Amputation}

A significantly higher proportion of men were amputated compared to women (23.5 vs. $6.5 \%$; p < 0.001). Older patients $(60.5 \pm 10.8$ vs. $57.3 \pm 14.6$ years; $\mathrm{p}<0.001)$ and those with longer disease duration (17.3 \pm 10.4 vs. $13.6 \pm 9.5$ years; $\mathrm{p}<0.001)$ had also a higher prevalence of amputation, as did patients with type 2 diabetes (14.4 vs. $6.6 \% ; \mathrm{p}=0.017$ ). Patients of Asian descent were less frequently amputated than those of White, Black or Mixed ethnicities (7.6 \% vs. 16.5, 10.8 and $12.2 \%$, respectively; $\mathrm{p}=0.043$ ). Those with retinopathy also had a higher prevalence of amputation (20.5 vs. $7.5 \%$; $\mathrm{p}<0.001)$, as did patients with visual (17.1 vs. $9.2 \%$; $\mathrm{p}<0.001)$ or renal impairment $(18.4$ vs. $9.9 \%$; $\mathrm{p}=0.001)$. Similar to what was found for ulcer, patients classified as having ischemic foot had a lower prevalence of amputation than those with neuropathic and neuroischemic foot (9.6 vs. 20.6 and $28.7 \%$, respectively; $\mathrm{p}<0.001$ ). Patients with hypertension also had a lower prevalence of amputation (12 vs. $20.4 \%$; $<<0.001$ ).

Table 3 shows the prevalence of clinical characteristics in patients with and without amputation.

\section{Moderate/severe neuropathic symptoms}

In the analysis of patients with moderate/severe vs. nor$\mathrm{mal} / \mathrm{mild}$ neuropathic symptom scores, those with higher (more severe) scores were more frequently female (53 vs. $45.8 \%$; $\mathrm{p}=0.01$ ), older ( $58.5 \pm 13$ vs. $56.4 \pm 15.5$ years; $\mathrm{p}=0.009)$ and had a higher BMI (29.95 \pm 6.58 vs. $28.92 \pm 5.79 ; \mathrm{p}=0.004)$. White patients were less frequently classified as having severe symptoms than those of Black, Mixed or Asian ethnicities (45.8 vs. 52.9, 54.5 and $57 \%$, respectively; $\mathrm{p}=0.02$ ). Patients with retinopathy had a higher prevalence of severe symptoms (52.7 vs. $45.8 \%$; $\mathrm{p}=0.02$ ), as did those with visual impairment (54.1 vs. $46.1 \% ; \mathrm{p}=0.006)$. In contrast to what was found for amputation and ulcer, patients from the emerging regions had a higher prevalence of severe symptoms than those coming from developed regions (57.3 vs. $44.9 \%$, respectively; $\mathrm{p}<0.001)$.

Table 4 shows the prevalence of clinical characteristics in patients with normal/mild and moderate/severe symptoms.

\section{Independent risk factors for ulcer and amputation}

Multivariate regression analyses are summarized in Table 5. Independent risk factors for ulcer were male gender, smoking, foot at risk classification (highest risk associated with the neuroischemic group and lowest to the ischemic group), region of origin (higher risk for those from more economically developed regions), presence of retinopathy and absent vibratory sensation. Risk factors for amputation were male gender, type 2 diabetes, foot at risk classification (higher risk for ischemic foot), hypertension (lower risk), region of origin (South/Southeast), previous history of ulcer and altered vibratory sensation. There was no association between the two outcomes and ethnicity in multivariate analyses.

This is the first large, comprehensive multicenter epidemiological study of foot at risk in diabetes outside Europe [9], Australia [11] or China [12]. We found the prevalence of previous ulcer to be 25 and $14 \%$ for amputation. Additionally, $18 \%$ of patients had an active ulcer at the time of evaluation. Although at a first glance the rate of active foot ulcers could be considered high when compared to the results of other studies (e.g. the FREEMANTLE Study) [11], there are some important differences. Our results are, at this time, from a transversal 
Table 2 Prevalence (\%) and means of clinical characteristics in patients with and without previous ulcer

\begin{tabular}{|c|c|c|c|}
\hline \multirow[t]{2}{*}{ Variable } & \multicolumn{2}{|c|}{ Previous ulceration } & \multirow[t]{2}{*}{$\mathbf{p}$} \\
\hline & Yes & No & \\
\hline Age (years) & 58.4 & 57.5 & 0.26 \\
\hline Sex (female/male) & $41.7 / 58.3$ & $64.4 / 35.6$ & $<0.001$ \\
\hline $\mathrm{BMI}\left(\mathrm{kg} / \mathrm{m}^{2}\right)$ & 29.4 & 29.3 & 0.88 \\
\hline Ethnicity & & & 0.008 \\
\hline White & 61.2 & 51.2 & \\
\hline Black & 14.4 & 20.1 & \\
\hline Mixed & 20 & 20.9 & \\
\hline Asian & 4.4 & 7.8 & \\
\hline Type of diabetes (1/2) & $9.9 / 90.1$ & $9.4 / 90.6$ & 0.77 \\
\hline Diabetes duration (years) & 17.2 & 13.2 & $<0.001$ \\
\hline HbA1c (\%) & 9.23 & 8.35 & $<0.001$ \\
\hline Smoking (yes) & 25.8 & 22.7 & 0.25 \\
\hline Hypertension (yes) & 80.3 & 82 & 0.49 \\
\hline Cardiopathy (yes) & 39.5 & 24.4 & $<0.001$ \\
\hline Dyslipidemia (yes) & 71.2 & 73.5 & 0.45 \\
\hline Nephropathy (ClCr < 60 ml/min) & 29.6 & 18.8 & $<0.001$ \\
\hline Retinopathy (yes) & 69.8 & 38 & $<0.001$ \\
\hline Visual impairment (yes) & 63.3 & 46.1 & $<0.001$ \\
\hline Foot at risk classification & & & $<0.001$ \\
\hline Foot without risk & 7.9 & 48.6 & \\
\hline Neuropathic & 52.3 & 27.2 & \\
\hline Ischemic & 4.8 & 9.9 & \\
\hline Neuroischemic & 35 & 14.3 & \\
\hline Score of symptoms & & & 0.44 \\
\hline Normal/mild & 47.3 & 49.9 & \\
\hline Moderate/severe & 52.7 & 50.1 & \\
\hline Disability score & & & $<0.001$ \\
\hline Normal/mild & 53.1 & 80.5 & \\
\hline Moderate/severe & 46.9 & 19.5 & \\
\hline Treatment of neuropathy (yes) & 17.3 & 11.9 & 0.015 \\
\hline Region & & & 0.001 \\
\hline South/Southeast & 65.1 & 54.6 & \\
\hline Northeast/Midwest & 34.9 & 45.4 & \\
\hline
\end{tabular}

study and not prospectively evaluated. Additionally, the inclusion of centers with structured foot care units could have contributed to increase active ulcer prevalence. In the next years, in a prospective basis it will be possible to determine with more certainty if the prevalence of ulcers in patients with diabetes in Brazil is higher than in other parts of the world.

Fifty percent had moderate/severe neuropathic symptoms. These findings are in line with previous data [13, $14]$, especially that from developing nations $[15,16]$, except for the high proportion of patients with severe symptoms. Also noteworthy, despite the high number of
Table 3 Prevalence (\%) and means of clinical characteristics in patients with and without previous amputation

\begin{tabular}{|c|c|c|c|}
\hline \multirow[t]{2}{*}{ Variable } & \multicolumn{2}{|c|}{ Previous amputation } & \multirow[t]{2}{*}{$p$} \\
\hline & Yes & No & \\
\hline Age (years) & 60.5 & 57.3 & 0.001 \\
\hline Sex (female/male) & $29.1 / 70.9$ & $63.3 / 36.7$ & $<0.001$ \\
\hline $\mathrm{BMI}\left(\mathrm{kg} / \mathrm{m}^{2}\right)$ & 28.7 & 29.4 & 0.18 \\
\hline Ethnicity & & & 0.043 \\
\hline White & 63.3 & 51.7 & \\
\hline Black & 14.8 & 19.6 & \\
\hline Mixed & 18.1 & 21.1 & \\
\hline Asian & 3.8 & 7.7 & \\
\hline Type of diabetes $(1 / 2)$ & $4.2 / 95.8$ & $9.5 / 90.5$ & 0.017 \\
\hline Diabetes duration (years) & 17.3 & 13.6 & $<0.001$ \\
\hline $\mathrm{HbA} 1 \mathrm{c}(\%)$ & 8.76 & 8.54 & 0.4 \\
\hline Smoking (yes) & 26.1 & 23.9 & 0.52 \\
\hline Hypertension (yes) & 72.2 & 83 & 0.001 \\
\hline Cardiopathy (yes) & 36.4 & 26.8 & 0.023 \\
\hline Dyslipidemia (yes) & 65 & 74.3 & 0.022 \\
\hline Nephropathy $(\mathrm{ClCr}<60 \mathrm{ml} / \mathrm{min})$ & 33.3 & 19.7 & 0.001 \\
\hline Retinopathy (yes) & 69.8 & 42.1 & $<0.001$ \\
\hline Visual impairment (yes) & 65 & 47.7 & $<0.001$ \\
\hline Foot at risk classification & & & $<0.001$ \\
\hline Foot without risk & 3.3 & 43.9 & \\
\hline Neuropathic & 49.5 & 30.6 & \\
\hline Ischemic & 6 & 9.1 & \\
\hline Neuroischemic & 41.2 & 16.4 & \\
\hline Score of symptoms & & & 0.7 \\
\hline Normal/mild & 47.9 & 49.5 & \\
\hline Moderate/severe & 52.1 & 50.5 & \\
\hline Disability score & & & $<0.001$ \\
\hline Normal/mild & 39.1 & 79.2 & \\
\hline Moderate/severe & 60.9 & 20.8 & \\
\hline Treatment of neuropathy (yes) & 19.3 & 11.5 & 0.005 \\
\hline Region & & & 0.069 \\
\hline South/Southeast & 62.4 & 55.4 & \\
\hline Northeast/Midwest & 37.6 & 44.6 & \\
\hline
\end{tabular}

patients with symptoms, we found that only $14 \%$ were receiving medication for neuropathic pain relief.

Our patients had a unique combination of characteristics. The major difference between our patients and those evaluated in studies from the USA [17] or Western Europe [18] is a higher proportion of patients with neuropathic disease, with clear predominance of the neuroischemic population, and a smaller number of patients with isolated ischemic disease. Most studies conducted in economically developed nations show a high prevalence of ischemic disease $[19,20]$. Similar findings had been found in one of the centers involved in our study, 
Table 4 Prevalence (\%) and means of clinical characteristics in patients with normal/mild and moderate/severe symptoms

\begin{tabular}{|c|c|c|c|}
\hline \multirow[t]{2}{*}{ Variable } & \multicolumn{2}{|c|}{ Score of symptoms } & \multirow[t]{2}{*}{$\mathrm{p}$} \\
\hline & Normal/mild & Moderate/severe & \\
\hline Age (years) & 56.4 & 58.5 & 0.009 \\
\hline Sex (female/male) & $56 / 63$ & $44 / 37$ & 0.01 \\
\hline BMI $\left(\mathrm{kg} / \mathrm{m}^{2}\right)$ & 28.9 & 29.9 & 0.004 \\
\hline Ethnicity & & & 0.024 \\
\hline White & 58 & 49.8 & \\
\hline Black & 16.9 & 19.2 & \\
\hline Mixed & 18.4 & 22.4 & \\
\hline Asian & 6.7 & 8.5 & \\
\hline Type of diabetes (1/2) & 10.3/89.7 & 7.9/92.1 & 0.12 \\
\hline Diabetes duration (years) & 13.9 & 14.4 & 0.3 \\
\hline $\mathrm{HbA1c}(\%)$ & 8.66 & 8.46 & 0.26 \\
\hline Smoking (yes) & 25.2 & 25.4 & 0.94 \\
\hline Hypertension (yes) & 80.1 & 84.1 & 0.063 \\
\hline Cardiopathy (yes) & 26.4 & 30.9 & \\
\hline Dyslipidemia (yes) & 71.1 & 75 & 0.15 \\
\hline $\begin{array}{l}\text { Nephropathy }(\mathrm{ClCr}<60 \mathrm{ml} / \\
\text { min) }\end{array}$ & 22.4 & 21.5 & 0.48 \\
\hline Retinopathy (yes) & 42.3 & 49.1 & 0.024 \\
\hline Visual impairment (yes) & 46.1 & 54.1 & 0.006 \\
\hline Foot at risk classification & & & $<0.001$ \\
\hline Foot without risk & 53.8 & 27.1 & \\
\hline Neuropathic & 19.4 & 41.4 & \\
\hline Ischemic & 11.2 & 5.8 & \\
\hline Neuroischemic & 15.5 & 25.7 & \\
\hline Previous ulceration (yes) & 22.3 & 24.2 & 0.44 \\
\hline Previous amputation (yes) & 12.6 & 13.3 & 0.7 \\
\hline $\begin{array}{l}\text { Treatment of neuropathy } \\
\text { (yes) }\end{array}$ & 11.4 & 17.9 & 0.003 \\
\hline Region & & & $<0.001$ \\
\hline South/Southeast & 64.2 & 52.1 & \\
\hline Northeast/Midwest & 35.8 & 47.9 & \\
\hline
\end{tabular}

but with a higher proportion of isolated neuropathic disease [21]. Mean age (57 years old) was also younger than that reported for patients from Western Europe [22] and North America [23]. On the other hand, characteristics like longer disease duration and high frequency of associated comorbidities are in line with data from developed nations [18-23].

Individuals with more severe symptoms were more commonly overweight, older and female. The relation between BMI and symptoms of neuropathy could be associated with other obesity related comorbidities or with excessive load on the lower extremities. Ulcer and amputation were less common in patients of Asian descent, a fact already reported in other studies [24]. However, in
Table 5 Multivariate regression analyses of factors influencing the risk of ulcer and amputation

\begin{tabular}{|c|c|c|c|}
\hline Factor & OR & $95 \% \mathrm{Cl}$ & $\mathbf{p}$ \\
\hline \multicolumn{4}{|l|}{ Ulcer } \\
\hline Male sex & 1.71 & $1.12 ; 2.59$ & 0.011 \\
\hline Smoking & 1.78 & $1.09 ; 2.89$ & 0.019 \\
\hline Neuropathic foot & 9.96 & $4.85 ; 20.43$ & $<0.001$ \\
\hline Ischemic foot & 5.64 & $1.9 ; 16.7$ & 0.002 \\
\hline Neuroischemic foot & 20.34 & $9.31 ; 44.38$ & $<0.001$ \\
\hline Decreased vibratory sensation & 1.36 & $0.82 ; 2.24$ & 0.23 \\
\hline Absent vibratory sensation & 7.95 & $4.65 ; 13.59$ & $<0.001$ \\
\hline Retinopathy & 1.68 & $1.08 ; 2.62$ & 0.022 \\
\hline Region (South/Southeast) & 2.39 & $1.47 ; 3.87$ & $<0.001$ \\
\hline \multicolumn{4}{|l|}{ Amputation } \\
\hline Male sex & 2.12 & $1.2 ; 3.73$ & 0.009 \\
\hline Type 2 diabetes & 3.33 & $1.01 ; 11.1$ & 0.049 \\
\hline Neuropathic foot & 5.8 & $1.25 ; 26.9$ & 0.025 \\
\hline Ischemic foot & 19.63 & $3.43 ; 112.5$ & 0.001 \\
\hline Neuroischemic foot & 11.6 & $2.43 ; 55.33$ & 0.002 \\
\hline Decreased vibratory sensation & 2.4 & $1.09 ; 5.3$ & 0.03 \\
\hline Absent vibratory sensation & 3.46 & $1.64 ; 7.33$ & 0.001 \\
\hline Hypertension & 0.3 & $0.14 ; 0.63$ & 0.002 \\
\hline Region (South/Southeast) & 2.2 & $1.1 ; 4.42$ & 0.027 \\
\hline Previous ulcer (yes) & 9.66 & $4.67 ; 19.98$ & $<0.001$ \\
\hline
\end{tabular}

multiple adjusted regressions, ethnicity was not a factor associated with either outcome. We believe that this is due to the historic and strong miscegenation typical of our country's population. Social and economic factors are probably more associated with these ethnic differences in terms of the prevalence of ulcer and amputation [25].

Indeed, ulcer and amputation were more common in the more developed regions of the country, which may be related to the greater prevalence of other diseases such as obesity and metabolic syndrome [26]. Also, social and economic differences might play an important role, in conjunction with disparities in health care access. Increased awareness by health care professionals and more swiftly available access to specialty centers could result in increased diagnosis, which in turn is reflected in an increase in apparent prevalence. Additionally, diabetes prevalence is higher in the South and Southeast regions of the country [27].

Regarding factors independently associated with ulcer risk, the finding that men have an increased risk of ulcer is in accord with the great majority of previous studies $[9,11,12,21,22,25]$. This fact is associated with disease progression and also with social facts related to men being more frequently family providers and consequently showing lower adherence to medical visits and wound care [28]. 
Loss of vibratory sensation and large fiber damage are frequently seen as the first sensations affected by distal diabetic polineuropathy [29]. Retinopathy is also a longterm complication of diabetes and is expected to co-exist with neuropathy. In addition, it can make self-care and self-examination more difficult and thus predispose to ulcer. In adjusted analysis, however, visual impairment was not an associated risk factor, indicating that microvascular processes occurring simultaneously is a more likely explanation for ulcer than visual deficits.

The lowest risk for ulcer relative to foot at risk classification when compared to foot without risk was isolated arterial disease. The greatest risk was linked to neuroischemic disease. The combination of neuropathy and peripheral arterial disease has been associated with a high ulcer risk in most previous studies [9, 11, 21], but ischemia is normally associated with a greater risk than neuropathy $[9,30]$. This difference might be due to neuropathy being more common in developing countries. Similar findings have been published in smaller studies from other emerging nations $[12,15,16,21]$. A younger age at presentation and a lower prevalence of obesity and other associated diseases apart from diabetes itself may combine to expose patients to ulcer sooner than atherosclerotic disease manifests.

As reported for ulcer, male sex is associated with a greater risk of amputation in almost all studies on diabetic foot complications. In the case of type 2 diabetes, it is more commonly associated with other comorbidities that can predispose to poorer outcomes in ulcer, such as obesity, insulin resistance, dyslipidemia and atherosclerosis [31], thus explaining the greater risk of amputation, even in a younger population. Loss of vibratory sensation and previous ulcer are established risk factors for amputation. Amputation is, in fact, a last resort treatment for diabetic ulcers.

Unlike ulcer, patients presenting ischemic disease, either in an isolated form or associated with neuropathy presented the greatest risk for amputation in multivariate analysis. Ischemic disease has frequently been associated with poorer ulcer outcomes $[9,11]$, especially when associated with infection [32], explaining the higher probability of ending in amputations. The finding of hypertension being associated with a lower risk for amputation even in adjusted analysis was a surprising one, and no clear explanation could be found for this fact with the current data. Follow up results may cast some light on this matter.

This study has some limitations. The data represent baseline information, and the causative factors here identified have the constrictions inherent to cross sectional evaluations. However, all the risk factors found for ulcer and amputation are well recognized in the literature, which makes us more confident that our estimates are adequate. Another limitation is that we found a relatively high number of patients referred for evaluation who in the end were revealed to present foot without risk. Although serving as a reference category to estimate the risk of neuropathy vs. ischemia for ulcer and amputation, the relatively small number of patients with foot at risk could have underpowered our analysis. Nevertheless, we were able to identify several risk factors associated with those conditions, a detail that reassures us that the analysis deserves merit. Additionally, our population was a large one, and the fact that patients came from several different centers and were primary care referrals support the representativeness of our sample. As with any other studies using ABI for ischemic disease diagnosis, the prevalence of ischemic disease could have been underrepresented, but this methodology has been used in most studies; therefore, data from this study is comparable to that in others. Whether our findings can be extrapolated to other South or Latin American populations is also debatable as our country bears significant ethnic and social differences from others in this region of the world.

\section{Conclusions}

In conclusion, we found a high prevalence of ulcer and amputation in patients with foot at risk in Brazil. Additionally, we found a younger age at presentation and that patients with ulcer presented a higher prevalence of neuropathy compared to ischemic foot at risk. Ischemic disease remains a factor associated with amputations, probably as a determinant of poorer ulcer outcomes, as reported in other studies. Ethnic differences were not of great importance in a miscegenated population, and probably only reflect social and economic differences as well as health care access disparities. We hope the data presented here can contribute to the fast growing literature on diabetic foot and to understanding regional differences in factors affecting the prevalence of ulcer and amputation. This study will continue to follow up patients presenting with ulcer and data on their outcomes are expected in the next couple of years.

\section{Authors' contributions}

MCRP conceived of the study, and participated in its design and coordination and helped to draft the manuscript. AMN helped to draft the manuscript. AMN and MJAS contributed to analyzing, reviewed and edited the data. FHM, MBG,RMT, JEPO,JRDP, RMCF, LBAG, ACF, AMAO, MBMN, VNQC, HS, OHN, MN, TDF, HCP, CSSO, MR, KFR, MTQ, AEFV, GMCM, EGSP,KGID,AEP, ACFF, MRC have collected the data. MCRP had full access to all study data and was responsible for submitting the manuscript. All authors read and approved the final manuscript.

\section{Author details}

${ }^{1}$ Faculty of Medical Sciences, State University of Campinas, Campinas, SP 13083-887, Brazil. ${ }^{2}$ Unity of Diabetes, State University of Rio de Janeiro, Rio de Janeiro, Brazil. ${ }^{3}$ Department of Nutrology, Federal University of Rio de Janeiro, Rio de Janeiro, Brazil. ${ }^{4}$ Centre for Diabetes and Endocrinology in the State 
of Bahia (CEDEBA), Salvador, Brazil. ${ }^{5}$ Centro Integrado de diabetes e Hipertensão do Ceará, Fortaleza, Brazil. ${ }^{6}$ State University of Feira de Santana, Feira de Santana, Brazil. ${ }^{7}$ Federal University of Campina Grande, Campina Grande, Brazil. ${ }^{8}$ Hospital das Clínicas de Porto Alegre, Federal University of Rio Grande do Sul, Porto Alegre, RS, Brazil. ${ }^{9}$ Santa Casa de Porto Alegre, Porto Alegre, RS, Brazil. ${ }^{10}$ Hospital das Clínicas da Faculdade de Medicina, Universidade de São Paulo, São Paulo, Brazil. ${ }^{11}$ Hospital Regional de Taguatinga, Brasília, Brazil. ${ }^{12}$ Faculdade de Medicina, Federal University of Santa Catarina, Florianopolis, Brazil. ${ }^{13}$ Federal University of Sergipe, São Cristóvão, Brazil. ${ }^{14}$ Pontifícia Universidade Católica de Sorocaba, Sorocaba, Brazil. ${ }^{15}$ Division of Endocrinology, Hospital Agamenon Magalhães, Recife, Brazil. ${ }^{16}$ Faculdade de Medicina de Catanduva, Catanduva, Brazil. ${ }^{17}$ Faculdade de Medicina de Botucatu, UNESP, Botucatu, Brazil. ${ }^{18}$ Universidade de São Paulo, Faculdade de Medicina, Ribeirão Preto, Brazil. ${ }^{19}$ Santa Casa de Belo Horizonte, Belo Horizonte, Brazil.

\section{Acknowledgements}

The authors thank the National Institutes for Science and Research (INCT) Diabetes and Obesity and the National Center for Science and Technology Development (CNPq) for funding this study.

\section{Competing interests}

The authors declare that they have no competing interests.

\section{Received: 28 August 2015 Accepted: 25 January 2016} Published online: 17 March 2016

\section{References}

1. Wild S, Roglic G, Green A, Sicree R, King H. Global prevalence of diabetes: estimates for the year 200 and projections for 2030. Diabetes Care. 2004;5:1047-53.

2. Fejfarová V, Jirkovská A, Dragomirecká E, Game F, Bém R, Dubský M, Wosková V, Křížová M, Skibová J, Wu S. Does the diabetic foot have a significant impact on selected psychological or social characteristics of patients with diabetes mellitus? J Diabetes Res. 2014;. doi:10.1155/2014/371938.

3. Viswanathan V, Wadud JR, Madhavan S, Rajasekar S, Kumpatla S, Lutale JK, Abbas ZG. Comparison of post amputation outcome in patients with type 2 diabetes from specialized foot care centers in three developing countries. Diabetes Res Clin Pract. 2010;88:146-50.

4. Izumi Y, Sattterfield K, Lee S, Harkless LB, Lavery LA. Mortality of first-time amputees in diabetics: a 10 year observation. Diabetes Res Clin Pract. 2009;83:126-31.

5. Apelqvist J, Bakker K, VAN Houtum WH, Schaper NC. International Working Group on the Diabetic Foot (IWGDF) Editorial Board. Practical guidelines on the management and prevention of the diabetic foot: based upon the International Consensus on the Diabetic Foot (2007) prepared by the International Working Group on the Diabetic Foot. Diabetes Metab Res Rev. 2008;24 Suppl 1:S181-7.

6. Alangh A, Chiu M, Shah BR. Rapid increase in diabetes incidence among Chinese Canadians between 1996 and 2005. Diabetes Care. 2013;10:3015-7.

7. Abbott CA, Garrow AP, Carrington AL, Morris J, Van Ross ER, Boulton AJ. Foot ulcer risk is lower in South-Asian and African-Caribbean compared with European diabetic patients in the U.K. Diabetes Care. 2005;28:1869-75

8. Rucker-Whitaker C, Feinglass J, Pearce WH. Explaining racial variation in lower extremitiy amputation: a 5-year retrospective claims data and medical record review at an urban teaching hospital. Arch Surg. 2003;138:1347-51.

9. Prompers L, Schaper N, Alpeqvist J, Edmonds M, Jude E, Mauricio D, Uccioli L, Urbancic V, Bakker K, Holstein P, Jirkovska A, Piaggesi A, Ragnarson-Tennvall G, Reike H, Spraul M, Van Acker K, Van Baal J, Van Merode F, Ferreira I, Huijberts M. Prediction of outcome in individuals with diabetic foot ulcers: focus on the differences between individuals with and without peripheral arterial disease. The EURODIALE study. Diabetologia. 2008;51:747-55.

10. Takolander R, Rauwerda JA. The use of non-invasive vascular assessment in diabetic patients with foot lesions. Diabetic Med. 1996;13:S39-42.

11. Davis WA, Norman PE, Bruce DG, Davis TM. Predictors, consequences and costs of diabetes-related lower extremity amputation complicating type 2 diabetes: the Freemantle Diabetes Study. Diabetologia. 2006:49:2634-41.

12. Hao D, Hu C, Zhang T, Feng G, Chai J, Li T. Contribution of infection and peripheral artery disease to severity of diabetic foot ulcers in Chinese patients. Int J Clin Pract. 2014;9:1161-4.

13. Moss SE, Klein R, Klein BE. The prevalence and incidence of lower extremity amputation in a diabetic population. Arch Intern Med. 1992;152:610-6.

14. Muller IS, de Grauw WJ, van Gerwen WH, Bartelink ML, van Den Hoogen HJ, Rutten GE. Foot ulceration and lower limb amputation in type 2 diabetic patients in Dutch primary health care. Diabetes Care. 2002;25:570-4.

15. Altindas M, Kilic A, Cinar C, Bingol UA. OrzukG. The epidemiology of foot wound in patients with diabetes: a description of 600 consecutive patients in Turkey. J Foot Ankle Surg. 2011;50:146-52.

16. Ekpebegh CO, Iwuala SO, Fasanmade OA, Ogbera AO, Igumbor E, Ohwovoriole AE. Diabetes foot ulceration in a Nigerian hospital: in-hospital mortalit in relation to the presenting demographic, clinical and laboratorial features. Int Wound J. 2009;6:381-5.

17. Boyko EJ, Ahroni JH, Cohen V, Nelson KM, Heagerty PJ. Prediction of diabetic foot ulcer occurrence using commonly available clinical information: the Seattle Diabetic Foot Study. Diabetes Care. 2006;6:1202-7.

18. Prompers L, Huijberts M, Alpeqvist J, Jude E, Piaggesi A, Bakker K, Edmonds M, Holstein P, Jirkovska A, Mauricio D, Tennvall GR, Reike H, Spraul M, Uccioli L, Urbancic V, Van Acker K, Van Baal J, Van Merode F, Schaper N. Delivery of care to diabetic patients with foot ulcers in daily practice: results of the Eurodiale study, a prospective cohort study. Diabet Med. 2008;25:700-7.

19. Lauterbach S, Kostev K, Becker R. Characteristics of diabetic patients visiting a podiatric practice in Germany. J Wound Care. 2010;19:140-4.

20. Lauterbach S, Kostev K, Kohlmann T. Prevalence of diabetic foot syndrome and its risk factors in the U.K. J Wound Care. 2010;19:333-7.

21. Moura Neto A, Zantut-Wittmann DE, Fernandes TD, Nery M, Parisi MC Risk factors for ulceration and amputation in diabetic foot: study in a cohort of 496 patients. Endocrine. 2013:44:119-24.

22. Säaman A, Tajiyeva O, Müller N, Tschauner T, Hoyer H, Wolf G, Müller UA. Prevalence of the diabetic foot syndrome at the primary care level in Germany: a cross-sectional study. Diabet Med. 2008;25:557-63.

23. Selby JV, Zhang D. Risk factors for lower extremity amputation in persons with diabetes. Diabetes Care. 1995;18:1079-89.

24. Chatuverdi N, Abbott CA, Whalley A, Widdows P, Leggetter SY, Boulton AJ. Risk of diabetes-related amputations in South Asians vs. Europeans in the UK. Diabet Med. 2002;19:99-104.

25. Margolis DJ, Jeffcoate WJ. Epidemiology of foot ulceration and amputation: can global variation be explained? Med Clin N Am. 2013;97:791-805.

26. Online database. http://www.abeso.org.br/uploads/ downloads/74/553a2473e1673.pdf. Accessed 24 July 2015

27. Schmidt MI, Duncan BB, Hoffmann JF, de Moura L, Malta DC, de Carvalho RMSV. Prevalence of diabetes and hypertension based on self-reported morbidity survey, Brazil, 2006. Rev Saúde Pública [Internet]. 2009 [cited 2015 July 24];43(Suppl 2):74-82.

28. Yu MK, Lyles CR, Bent-Shaw LA, Young BA. Sex disparities in diabetes process of care in high-risk patients. J Diabetes Res. 2013; doi:10.1155/2013/575814.

29. Boulton AJM, Malik RA, Arezzo JC, Sosenko JM. Diabetic somatic neuropathies. Diabetes Care. 2004;27:1458-86.

30. Dolan NC, Liu K, Criqui MH, Greenland P, Guralnik JM, Chan C, Schneider JR, Mandapat AL, Martin G, McDermott MM. Peripheral artery disease, diabetes and reduced lower extremity functioning. Diabetes Care. 2002;25:113-20.

31. Resnick HE, Jones K, Ruotolo G, Jain AK, Henderson J, Lu W, Howard BV. Insulin resistance, the metabolic syndrome and risk of incident cardiovascular disease in nondiabetic American Indians: the Strong Heart Study. Diabetes Care. 2003;26:861-7.

32. Prompers L, Huijberts M, Alpeqvist J, Jude E, Piaggesi A, Bakker K, Edmonds M, Holstein P, Jirkovska A, Mauricio D, RagnarsonTennvall G, Reike H, Spraul M, Uccioli L, Urbancic V, Van Acker K, van Baal J, van Merode F, Schaper N. High prevalence of ischaemia, infection and serious comorbidity in patients with diabetic foot disease in Europe. Baseline results from the Eurodiale study. Diabetologia. 2007;50:18-25. 